\title{
Microstructural Optimisation of Chill Cast Al-Si Eutectic Alloys
}

\author{
J. Asensio-Lozano*, B. Suárez-Peña ${ }^{*}$ and G. F. Vander Voort** \\ *Department of Materials Science and Metallurgical Engineering, The University of \\ Oviedo, 13 Independence St., E-33004 Oviedo, AS, SPAIN. \\ ***ehler, Ltd., 41 Waukegan Rd., P.O. Box 1, Lake Bluff, IL 60044-1699, USA.
}

One of the most used alloys of the Al-Si binary system is the eutectic composition. Their properties are influenced by the development of non-equilibrium microstructures under industrial processing conditions whose main features are: the grain size and volume fraction of the primary $\alpha-\mathrm{Al}$ phase [1]; the particle diameter and geometry of the primary silicon phase; the morphology of the eutectic [2-4], notably the shape of the Si cuboids, as well as the morphology of second-phase Fe based intermetallics present as contaminants in the commercial alloys. In general, the mechanical properties can be improved markedly by the addition of modifier elements that change the morphology of the eutectic Si varying it from acicular platelets seen as needles in the plane of polish, to granular Si particles [2, 5]. By adding refiner elements, it is possible to reduce the size, increase the volume fraction and disperse the tougher $\alpha-\mathrm{Al}$ dendrites.

Two objectives were pursued in the present investigation: the first one aimed at determining the effectiveness of modification by $\mathrm{Sr}$ and refinement with $\mathrm{Ti}$ added separately to a standard commercial alloy (Table 1 and 2). The second objective was to verify the usefulness of these elements in modifying the microstructure when the addition of Sr and Ti is simultaneous, using two different alloying levels (Table 2).

After adding $\mathrm{Ti}$, it was observed that this element is capable of removing any trace of the columnar structure, giving rise to a clustered-cellular morphology (Fig. 1). The addition of $\mathrm{Sr}$ enhances the formation of large highly branched, basaltic dendrites. Both $\mathrm{Ti}$ and $\mathrm{Sr}$ helped to increase the volume fraction of primary $\alpha$-Al illustrating their $\alpha$-forming nature (Table 2). On adding $\mathrm{Ti}$ and $\mathrm{Sr}$ at $0.05 \% \mathrm{Sr}$ and two different levels of $\mathrm{Ti}$, the $\alpha$-forming nature prevails although a loss in effectiveness is noted. As for the analysis conducted on $\mathrm{Si}$ particles, a reduction of its diameter was detected with Ti and with Sr. A synergistic effect was observed when $\mathrm{Ti}$ and $\mathrm{Sr}$ were added together leading to additional further refinement. The volume fraction of cuboids remained unaltered with the addition of Sr to the commercial alloy, but increased somewhat with $\mathrm{Ti}$ additions. The combined addition of $\mathrm{Ti}$ and $\mathrm{Sr}$ resulted in higher volume fractions of Si cuboids denoting the prevailing effect of Ti. The morphological changes of the eutectic can be followed in Fig.1(d)-(f) at higher magnification. As a summary, the addition of Ti alone was irrelevant, but Sr additions change the eutectic from acicular to granular. The interest, however, centers on the simultaneous addition of Ti and Sr: Ti has a tendency to coarsen the Si granules and also to dilute the eutectic, a matter that can be resolved at about $600 \times$.

\section{References}

[1] Murty BS, et al. M. Int Mater Rev 2002; 47: 3.

[2] Chaefer M. and Fournelle RA. Metall Mater Trans A 1996; 27A: 1293.

[3] Closset B, Gruzleski JE. AFS Trans. 1982; 90: 453.

[4] Khan S, et al. Mater Sci 1993; 28: 5957.

[5] Shiukumar S, et al. JOM 1991; 26. 

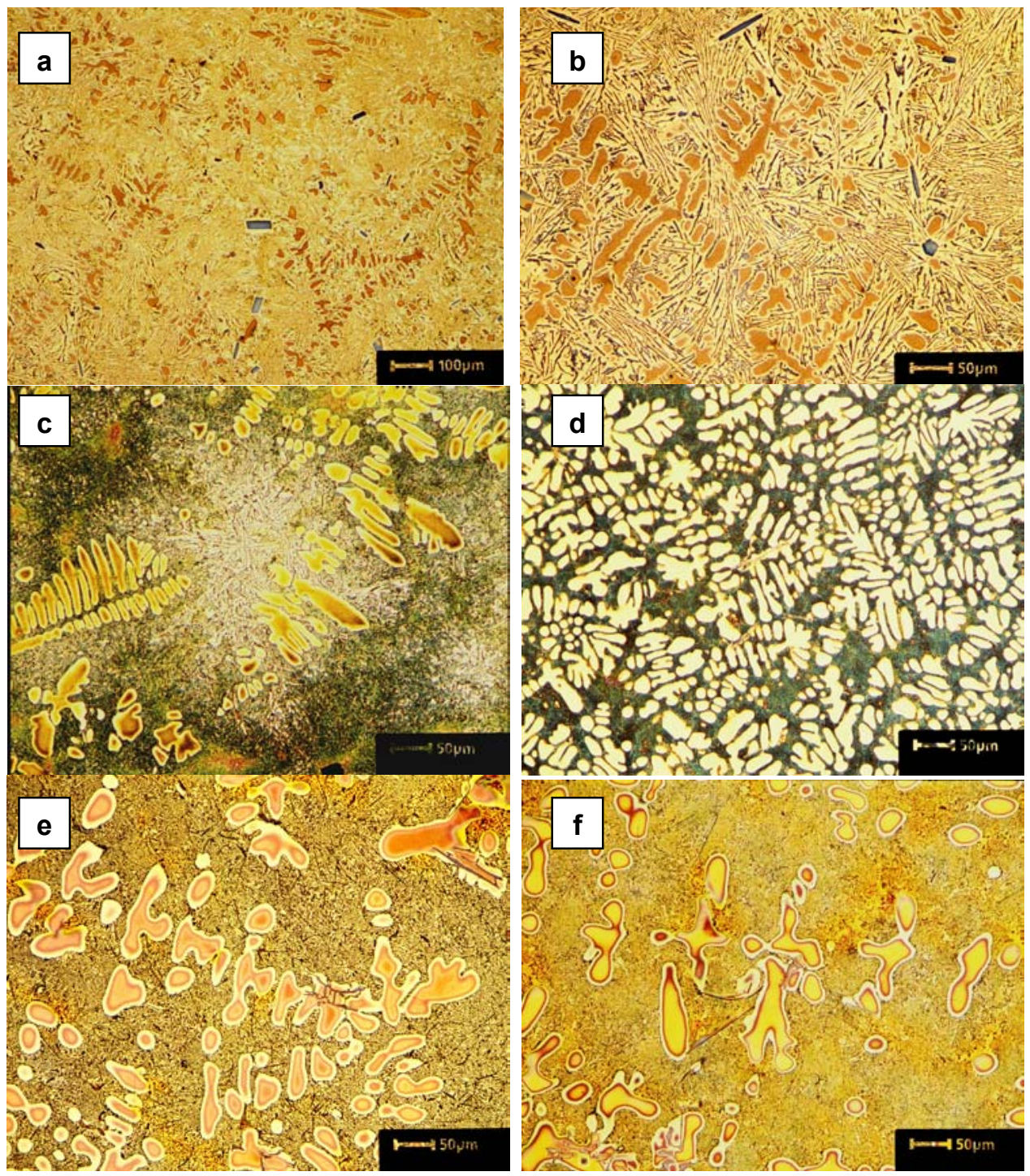

Fig. 1. Optical micrographs of studied compositions: (a)-(b) Al-12Si commercial alloy; (c) with 0.03 wt. $\%$ Ti; (d) with 0.04 wt. $\%$ Sr; (e) with 0.03 wt.\% Ti and 0.05 wt.\% Sr; and (f) with 0.05 wt. $\%$ Ti and 0.05 wt. $\% \mathrm{Sr}$.(scale bars $=50 \mu \mathrm{m}$, except for Fig.1(a) $=100 \mu \mathrm{m}$ ).

Table 1 Chemical composition of the Al-12Si base commercial alloy.

\begin{tabular}{cccccccccccc}
\hline Elements & $\mathrm{Si}$ & $\mathrm{Fe}$ & $\mathrm{Cu}$ & $\mathrm{Mn}$ & $\mathrm{Mg}$ & $\mathrm{Ni}$ & $\mathrm{Zn}$ & $\mathrm{Pb}$ & $\mathrm{Ti}$ & $\mathrm{Cr}$ & Other \\
\hline Content & 12.90 & 0.8 & 0.0 & 0.2 & 0.01 & 0.006 & 0.03 & 0.02 & 0.008 & 0.013 & 0.023 \\
\hline
\end{tabular}

Table 2. Details of $\mathrm{Sr}$ and $\mathrm{Ti}$ additions and relevant quantitative features measured.

\begin{tabular}{ccccccccc}
\hline \multirow{2}{*}{ Sample no. } & \multicolumn{2}{c}{ Basic Chemistry } & & $\alpha-\mathrm{Al}$ & \multicolumn{3}{c}{ Si-cuboids } \\
\cline { 7 - 8 } & Ti (wt.\%) & Sr (wt.\%) & & $f_{v}($ vol.\%) & $\bar{A}_{\alpha-A l}\left(\mu \mathrm{m}^{2}\right)$ & & $f_{v}($ vol.\% $)$ & $\bar{d}_{p}(\mu \mathrm{m})$ \\
\hline 1 & ---- & ----- & & 21.87 & 11296 & & 0.51 & 36.9 \\
2 & 0.03 & ----- & & 36.82 & 1085 & & 2.40 & 11.5 \\
3 & ----- & 0.04 & & 28.84 & 1639 & & 0.50 & 7.6 \\
4 & 0.03 & 0.05 & & 30.73 & 1455 & & 3.07 & 7.2 \\
5 & 0.05 & 0.05 & & 31.71 & 1302 & & 3.32 & 6.7 \\
\hline
\end{tabular}

